\title{
The effect of Siwan therapy in management of patients with rheumatoid arthritis: a single blind randomized controlled trial.
}

\author{
Nashwa M. Allam', Ghada M. Rashad Koura², Saud Mashi Alrawaili, Hamada Ahmed Hamada ${ }^{2 *}$, \\ Khater H.A ${ }^{4}$, Aladdin A. Balbaa ${ }^{2}$ \\ ${ }^{1}$ Faculty of Physical Therapy, 6 October University, Giza, Egypt \\ ${ }^{2}$ Faculty of Physical Therapy, Cairo University, Giza, Egypt \\ ${ }^{3}$ Department of Physical Therapy and Health Rehabilitation, College of Applied Medical Sciences, Prince Sattam, Bin \\ Abdulaziz University, Saudi Arabia \\ ${ }^{4}$ Faculty of Agriculture, Cairo University, Giza, Egypt
}

\begin{abstract}
Background: There is a growing interest in treatments involving natural means and procedures, alternative to those of conventional medicine. Some special sands are being used worldwide in therapeutic applications, especially in musculoskeletal problems.

Objectives: To compare the effect of Siwan traditional therapy versus conventional therapy for functional disability and pain in rheumatoid arthritis.

Design: A prospective, randomized, single-blind, pre-post-test, controlled trial. Setting: Four physical therapy departments in four multidiscipline, outpatient medical centers, located in Marsa Matrouh. The study was conducted between June 2015 and August 2016.

Participants: Thirty patient's rheumatoid arthritis (aged between 20 and 50 y) according to the American Rheumatism Association criteria 2010, participated in the study. Interventions: The patients were randomly assigned into 2 equal groups. Group (A) received Siwan traditional therapy in the form of sand bathing, followed by massage with olive oil for $\mathbf{7} \mathrm{d}$ and group (B) received conventional physical therapy for two months' day after day in the form of heat application, electrical stimulation (TENS), and exercise.

Main outcome measure: The primary outcome was pain severity measured by visual analogue scale while the secondary outcome was functional disability measured by Health Assessment Questionnaire (HAQ).

Results: Thirty patient with rheumatoid arthritis (group (A) $n=15$; group (B) $n=15$ ) were randomized and analysed. Comparing both groups post-program revealed that there were significant differences $(P<0.05)$ in pain level and HAQ between both groups with a significant reduction in favor of the group (A).

Conclusion: The Siwan therapy program was more effective than traditional physical therapy program in the treatment of rheumatic patients.
\end{abstract}

Keywords: Rheumatoid arthritis, Siwan therapy, Traditional physical therapy.

Accepted on January 23, 2018

\section{Introduction}

Rheumatoid Arthritis (RA) is an autoimmune disease affecting 0.5 to $1 \%$ of the adult population of developed regions which characterized by a chronic symmetrical polyarthritis of large and small joints, and by morning stiffness, which can lead to musculoskeletal impairment, and functional disabilities [1]. The burden of disease course varies and the prediction of the prognosis is difficult to estimate. In the long term, RA reduced function which leads to difficulties of doing daily living activities (ADL), and subsequently impact negatively on psychosocial aspect [2]. Furthermore, it relates to increased risk of osteoporosis [3] cardiovascular disease, and premature death. Mortality rates are more than twice as high in patients with RA as in the general population [4], and this gap appears to be widening [5].

Successful treatment to limit joint damage and functional loss requires early diagnosis, and of a multidisciplinary approach to managing physical, social, emotional and occupational impacts. The goal in treating RA is to induce complete 
remission. If remission is unable to be achieved, treatment aims to control disease activity and slow the rate of joint damage. Other treatment goals include alleviation of pain, maintenance of function for essential activities of the ADL and work, and maximization of quality of life [6]. Conventional treatments for RA, including Non-Steroidal Anti-Inflammatory Drugs (NSAIDs), Disease-Modifying Anti-Rheumatoid Drugs (DMARDs) and corticosteroids are rarely totally effective and some pharmacological therapies have the potential to cause side effects [7]. Among the strategies of non-pharmacological treatment of RA is physical exercises that address the development of range of movement, functional, cardiovascular capacity and muscular strength stand out generally, physical exercises are safe and recommended for patients with RA and other rheumatic diseases [8]. Moreover, RA has a substantial economic impact on patients, their families, and society) [9]. This may encourage more researches in traditional or natural therapy due to its characteristic Naturopathy are a form of alternative medicine based on a belief in 'vitalism [10]. Sand bathing can be grouped with other natural therapies, which include heat therapy, ray treatments, pressure of sand weight, and stimulate the hypothalamic-pituitary-adrenal axis. The important characteristics of sand bathing are its effect on a variety of diseases, its cheapness and few side effects. However, information on the effects of this therapy, mechanism of action, indications and contraindications for its use, hygiene standards of the sand bathing place, etc. is still scarce. To the authors' knowledge, there is no previous study considering the research on the siwan therapy on scientific base, helping in using the natural resources of Egypt and encourage medical tourism. Therefore, the aim of this study is to evaluate the impact of sand-bathing on pain and functional disability in patients with RA.

\section{Materials and Methods}

\section{Study design}

The study was designed as a prospective, randomized, singleblind, pre-post-test, controlled trial. Ethical approval was obtained from the institutional review board at Faculty of physical therapy, Cairo University before study commencement. The study was followed the Guidelines of Declaration of Helsinki on the conduct of human research. The study was conducted between June 2015 and August 2016.

\section{Study participants}

A convenient sample of thirty patients with rheumatoid arthritis from both genders was selected from four physical therapy departments in four multidisciplines, outpatient medical centers, located in Marsa Matrouh. They were enrolled and assessed for their eligibility to participate in the study. Their age ranged from 20 to $50 \mathrm{y}$. They were assessed and treated in Siwa oasis in The Marsa Matrouh Governorate. To be included in the study, patients with definite RA according to the 2010 American Rheumatism Association criteria [11], aged between 20 and $50 \mathrm{y}$, not bedridden, not wearing prostheses of a weight bearing joint, patients needed to be on stable doses of disease modifying anti-rheumatic drugs for $6 \mathrm{w}$ and NSAIDs for $2 \mathrm{w}$ before the study. Injections with corticosteroids in the 4 w before study was not permitted, and patients with pain of at least 3 to 7 on present pain intensity. Exclusion criteria were patients with uncontrolled arterial hypertension, diabetes, previous renal transplantation, coronary artery disease (unstable angina), pregnancy, and bleeding disorders. As well as patients who had received physiotherapy in the 6 months before the study: this was done to avoid possible carry-over effects of previous therapy.

\section{Randomization}

After a brief orientation session about the nature of the study and the tasks to be accomplished, they were randomly assigned into two equal groups (groups A and B) by a blinded and an independent research assistant who opened sealed envelopes that contained a computer generated randomization card. No subjects dropped out of the study after randomization. Written informed consent was obtained from all participants before the baseline evaluation.

\section{Interventions}

Participants, in group A, received Siwan therapy in the form of sand bathing, and massage with olive oil daily for $7 \mathrm{~d}$. The most beneficial time for a sand bath during summer's hottest months in June, July and August. Sand bathing was carried out on afternoon between $2 \mathrm{pm}$ and $4 \mathrm{pm}$ between June and August. The atmospheric temperature ranged between $40-45^{\circ} \mathrm{C}$, the surface temperature of the sand is $75-82^{\circ} \mathrm{C}$ and the temperature $10-20 \mathrm{~cm}$ under the sand surface is $50-60^{\circ} \mathrm{C}$ measured by an infrared thermometer (Medisana, Made in Germany). A hole dug of $20-40 \mathrm{~cm}$ in depth, $80 \mathrm{~cm}$ in width and $1.0-1.5 \mathrm{~m}$ in length. A long shallow hole was dug in the early morning to allow the sun's rays to heat the sand, and after the patient has lain himself down, he was covered to the neck with hot dry sand from the surface of the desert. The burial lasts for about $20 \mathrm{~min}$ during which time. When the sand becomes damp with sweat, it is replaced by fresh hot sand.

Afterward, the patient is wrapped in a towel and remains in a well-sealed tent pitched close to the burial area for $15 \mathrm{~min}$. All patients drink the liquids to prevent dehydration, drinking water was prohibited at this point. While in the tent, the body returns to its normal temperature and regain the resting status. The patients were wrapped to prevent the wind or air draft, which may lead to adverse effects such as stiff muscles or a pounding headache. Some advices gave to patients after treatment program: lie on the bed until his body acclimatizes to the cooler temperature, before the sweat on his shirt starts to get cold, change into dry clothes, use a towel to dust his body off from the sand as he dries, constantly replenish your body with fluids (anise, paddock, licorice, lemon juice). Some advices gave to patients before and during treatment program: don't use any creams or lotions before treatment, you will get very sandy and you will not be able to shower, when your body dries, the sand will dust off easily, use hot water when washing 
your hands and face, avoid getting water on other parts of your body, do not drink cold liquids, do not use fans or air conditioners at any point, until three days after treatment, and drink lots of fluids to keep your body working efficiently.

Participants, in group B, received traditional physical therapy exercise program, three sessions/w for two successive months. The program included hot application for about $20 \mathrm{~min}$ to elevate skin temperature and activate optimal heat loss responses by the body [12], Transcutaneous Electrical Nerve Stimulation (TENS): using Burst-mode TENS combines elements of both the high- and low frequency modes. In burst mode, the carrier frequency of the current is high $(70-100 \mathrm{~Hz})$, but it is delivered in small bursts at a low rate (3-4 bursts per second). Burst mode also uses motor-level stimulation. Electrode placements are placed over motor points of muscles in the myotomes related to the painful joint. This method produces longer-lasting pain relief applied for about $30 \mathrm{~min}$ [13], and exercise session for $30 \mathrm{~min}$ and was divided into 3 bouts of exercise separated by $1 \mathrm{~min}$ rest periods. The training includes cycle ergometer, leisure walking, and arm exercise. For the training of cycle ergometer, the load on the bicycle ergometers was applied at a resistance which achieved and maintained $70 \%$ of the maximum heart rate at $50 \mathrm{rpm}$, each session was preceded by a warm-up and ended with a cooldown [14].

\section{Outcomes}

Primary outcome (pain level): The primary outcome was pain, assessed on a $10 \mathrm{~cm}$ Visual Analogue Scale (VAS), where $0 \mathrm{~cm}$ represented no pain and $10 \mathrm{~cm}$ (killing pain). The patient places a mark along the line to denote his/her level of pain [15].

Secondary outcome (Berg balance scale): The secondary outcome was physical function assessed with the Health Assessment Questionnaire (HAQ). It included 20 questions in eight sections: dressing and grooming, arising, eating, walking, hygiene, reach, grip, and common daily activities. With four response categories were 0 , able without any difficulty; 1 , able with some difficulty; 2, able with much difficulty; and 3, unable. The highest response within each section was used as a score for that function. For the total HAQ score, the sum of the highest response in each section was divided by 8 to form a score with the range 0 to 3 [16].

\section{Sample size and statistical analyses}

To avoid a type II error, a preliminary power analysis (power $(1-\alpha$ error $P)=0.80, \alpha=0.05$, effect size $=1.1$, with a two-tailed for a comparison of 2 independent groups) determined a sample size of 15 for each group in this study. This effect size was calculated according after a pilot study on 12 participants (6 in each group) considering pain as a primary outcome. Sample size and power calculations were performed using $G$ power 3.1 Software. All statistical measures were performed using the Statistical Package for Social science (SPSS) program version 20 for windows. Prior to final analysis, data were screened for normality assumption, and presence of extreme scores. This exploration was done as a pre-requisite for parametric calculation of the analysis of difference and analysis of relationship measures. Testing for the homogeneity of covariance using Box's test revealed that there was no significant difference with $p$ values of $>0.05$. Normality test of data using Shapiro-Wilk test was used, that reflect the data was normally distributed for pain level and HAQ. All these findings allowed the researchers to conduct parametric analysis. So, two-way MANOVA was used to compare the tested variables of interest at different tested groups and measuring periods. Results are expressed as mean \pm Standard Deviation (SD). The alpha level was set at 0.05 .

\section{Results}

A total of 35 patients with RA were eligible for inclusion, and 30 were randomized for study intervention. The patients were randomly assigned into 2 equal groups. Group A received Siwan traditional therapy in form of sand bathing, followed by massage with olive oil for $7 \mathrm{~d}$ and group $\mathrm{B}$ received conventional physical therapy for two months' day after day in the form of hot application, electrical stimulation (TENS), and exercise. All randomized patients completed the trial. The groups were similar at baseline $(\mathrm{P}>0.05)$ with regard to age, height, weight, BMI, pain level and the secondary outcome measure HAQ (Tables 1 and 2).

Statistical analysis revealed that there were significant within subject effect $(\mathrm{F}=51.111, \mathrm{p}=0.0001)$ and between subject effect $\left(\mathrm{F}=9.141, \mathrm{p}=0.001^{*}\right)$. While there was no significant treatment $\times$ time effect $(\mathrm{F}=2.719, \mathrm{p}=0.075)$. Table 1 present descriptive statistic and multiple pairwise comparison tests (Post hoc tests) for the all dependent variables. In the same context regarding within subject effect, the multiple pairwise comparison tests revealed that there was significant reduction $(p<0.05)$ in pain level in the post treatment condition compared with the pretreatment at both groups. As well as, there was significant reduction $(\mathrm{p}<0.05)$ in HAQ in the post treatment condition compared with the pre-treatment at group A only. Regarding between subject effects multiple pairwise comparisons revealed that there was significant difference of pain level and HAQ between both groups $(\mathrm{p}<0.05)$ and this significant reduction in favor to group $\mathrm{A}$.

Table 1. Physical characteristics of patients with RF in both groups.

\begin{tabular}{llll}
\hline Characteristic & Group A & Group B & \multirow{2}{*}{ P-value } \\
\cline { 2 - 3 } & Mean \pm SD & Mean \pm SD & \\
\hline Age & $41.73 \pm 8.95$ & $42.53 \pm 9.36$ & 0.813 \\
\hline Height & $165.26 \pm 8.53$ & $168.46 \pm 7.96$ & 0.298 \\
\hline Weight & $78.13 \pm 15.35$ & $79.93 \pm 14.36$ & 0.743 \\
\hline
\end{tabular}

Table 2. Descriptive statistics for the all dependent variables for both groups at different measuring periods.

\begin{tabular}{lll}
\hline Variables Group A Group B &
\end{tabular}




\begin{tabular}{lllll} 
& \multicolumn{1}{l}{ Pre } & Post & Pre & Post \\
\cline { 2 - 4 } Pain level & $\begin{array}{l}74.28 \\
10.71\end{array}$ & $\pm 37.14 \pm 18.05$ & $81.07 \pm 9.84$ & $51.07 \pm 13.32$ \\
\hline HAQ & $1.75 \pm 0.58$ & $0.82 \pm 0.5$ & $1.82 \pm 0.52$ & $1.58 \pm 0.67$ \\
\hline Within groups (Pre vs. post) & & \\
\hline p-value & Pain level & HAQ \\
\hline Group A & $0.0001^{*}$ & $0.0001^{*}$ \\
\hline Group B & $0.0001^{*}$ & 0.247 \\
\hline Between groups (group A vs. group B) & \\
\hline p-value & Pain level & HAQ \\
\hline Pre treatment & 0.112 & 0.56 \\
\hline Post treatment & $0.005^{*}$ & $0.0001^{*}$ \\
\hline "Signifant & & \\
\hline
\end{tabular}

"Significant at the alpha level $(p<0.05)$, HAQ: Health Assessment Questionnaire

\section{Discussion}

This is the first the study to investigated the effects of Siwan therapy program versus traditional physical therapy program in management patients with rheumatoid arthritis. The results of this randomized controlled trial revealed that there was significantly reduction in pain level and functional disability when compared pre-treatment to post treatment in group received Siwan therapy. While, there was significantly reduction in pain level but there was no significant difference in functional disability when compared pre-treatment to post treatment in group received traditional physical therapy. Moreover, Siwan program by sand bathing, and massage with olive oil for $7 \mathrm{~d}$ improved pain (50\%) and functional disability (53.14\%) from traditional program (37.01\% and $13.19 \%$, respectively). This reflects that Siwan therapy program showed marked improvement in pain and functional disability compared to traditional physical therapy program. In consistent results, thermal therapy decrease pain and led to a better clinical course and out comes in patient with chronic pain [17]. Dillxat et al. [18] found that joint pain was relieved significantly in rheumatoid arthritis patients by serial sand bathing. This improvement in pain and functional disability may be attributed to explanation by Kirschner et al. [19] for vitalism which is the belief that living things depend on the action of a special energy called vital energy guides body processes such as metabolism, reproduction, growth, and adaptation. Moreover, Thakur [20] and Biswas et al. [21] reported that the different treatment modalities of naturopathy like sand therapy facilitate to keep the internal organs clean by removing the accumulated toxics matter from the tissues and strengthen them to perform their normal functions efficiently. Also, Jack [10] observed that the vital force affected by many factors including physical, mental, emotional, spiritual and environmental. A person's vital force determines their susceptibility to illness, the amount of treatment necessary, and the speed of recovery.
Environmental conditions of Siwa Oasis distinguished by a geographical location as the Oasis level is below sea level: it ranges from zero to $18 \mathrm{~m}$, hot and dry climate conditions in summer environment free from pollution and noise so its environment attracted the patients for medical tourism as it may encourage self-healing and increase their vital force. As the atmospheric temperature in Siwa ranged between $40-45^{\circ} \mathrm{C}$, sand is composed of fine grains interspersed with air. Being a porous system, it is characterized by low heat conductivity. Therefore, the sand system is able to release the heat absorbed from the sun's rays without causing burns, in spite of its high thermal gradient [22].

Based on the obtained results, the Siwan sand path is very effective in relieving pain and improving the function utilizing the thermal effect of sand especially in uncomplicated RA. In the RA, since the peripheral circulation is generally below the normal level, this is one of the causes of the pain [18]. Delivery of $\mathrm{O}_{2}$ and nutrients and removal of waste products $\left(\mathrm{CO}_{2}\right.$, lactic acid, etc.) and inflammatory substances (kinin, thromboxane, leukotriene, PAF, etc.). Moreover, Sand bathing has the influence for metabolism and organic function, and it has a strong effect on vasodilation and therefore it may suit most of rheumatoid arthritis [23].

One should also consider that analysis of Siwa sand represented enriching in $\mathrm{Ca}, \mathrm{Mg}$, silicon, carbon and other chemical elements. These elements become free and available to pass through the epidermis and to be absorbed into dermis cells, $\mathrm{Ca}$ under the ionic form $\mathrm{Ca}^{+2}$ is essential for the functional integrity of both muscular and nervous systems, and for the normal cardiovascular function. Also, it is well established that $\mathrm{Ca}$ therapy in simultaneous with vitamin D therapy increases the capacity for $\mathrm{Ca}$ absorption. Magnesium very important for human health. Under the form of $\mathrm{Mg}^{+2}$ it produces well known effects based on animal experimentation or tests "in vivo" reduces cardiovascular pathologies, since it has an important role in the metabolism of fats or lipids [22]. So, the sand therapy is important for human health and may help in musculoskeletal pathology and improving functional disability. Also exposure to sunlight during sand path provides the body with vitamin D.

Vitamin D (Vit. D) is a prohormone which synthesized in humans following skin exposure to ultraviolet $\mathrm{B}$ radiation in the range of 280-320 nm [24]. The Vit. D function not only in calcium metabolism and bone formation, but also their interaction with the immune system function [25]. Vitamin D seems to interact with the immune system through its actions on the regulation and differentiation of cells like lymphocytes, macrophages, and natural killer cells, besides cytokines production with a reduction in Interleukin (IL)-2, interferon gamma, and Tumor Necrosis Factor (TNF); inhibition of the expression of IL-6; and inhibition of the secretion and production of autoantibodies by B lymphocytes [26]. Currently, Vit. D deficiency lead to several autoimmune disorders, including insulin pendent diabetes mellitus, multiple sclerosis, inflammatory bowel disease, systemic lupus erythematosus, and RA [27,28]. Marine sand has long been 
found to relieve arthritic pain and reduce inflammation. The benefits of a $25 \mathrm{~min}$ hot sand burial were first documented in the region of Siwa in Cairo, Egypt in ancient times. From Egypt, this form of therapy spread throughout the sandy desert provinces of North Africa and the Middle East. In recent years, Sand Therapy has become a popular feature in European and Asian spas and it's slowly finding its way into American spas [29].

The scientific principle for holistic effects lies in the Egyptian belief that stagnant, impure water in the body causes disease. A burial or bath in hot sand is reported to remove about 3-4 L of water from the body in the form of sweat. By ridding the body of these impurities, symptoms are ameliorated in various conditions such as arthritis, gout and connective tissue disorders. Sand bath therapy is also reported to improve seasonal affective disorder, lower cholesterol levels, heal psoriasis and cure impotence. In 1966, the German chemist Bedouno Sanouni analysed the sand near Siwa. In particular, he measured the radon content and found it to be, as suspected, higher than that of nearby regions. Geological studies showed high amounts of silica carbonates along with high amounts of iron and magnesium. Radon spa therapies (/kc-morgan/v8227f) have long been used and are especially recommended as spa therapies for people with rheumatological disorders [29]. As well massage may help in decrease pain through improve circulation, muscle relaxation and its effect on mood this finding agree with Kavuncu and Evcik, [30] study who mention that the massage is found to be effective on depression, anxiety, mood, and pain. Also, massage decreases stress hormone levels.

On the other hand, decreasing of pain level by traditional physical therapy may be explained throughout the analgesic effect of heat and its effect on circulation, also the pain may be decreased through the mechanism of action of TENS for pain relieve by two theories: gate control theory [31] and the other theory postulated mechanisms of the pain relief mediated by TENS include the promotion of endorphin release in the brain [32] and local dilatation of blood vessels in injured tissue [33].

While functional disability not significant by traditional therapy may be due to the effect of TENS on pain as it effects on pain gait theory this relieve pain but not affect main cause of pain so may not effect on functional activity level. The patients were in active state during the treatment and they may need rest till inflammation subside and then start exercise program. These results accordance with Jong et al. [34] evaluated the effect and safety of a long-term exercise program compared with usual therapy. Iversen et al. [35] showed a trend toward more progressive joint damage in the exercise intervention groups, approximately $58 \%$ of rheumatologists in an arthritis center believe aerobic exercises are not useful for RA patients. Finckh et al. [36] who suggested inflamed joints to rest reduces local and systemic signs of inflammation. Exercise was not recommended to patients with rheumatic diseases for fear of exacerbating inflammation [37]. On the other hand, controlled studies suggest that exercise improves symptomatology and function. Regular prolonged exercise improves aerobic capacity, muscle strength, joint mobility, functional ability, and mood by as much as $57 \%$, without apparent increases in joint symptoms or disease activity [38] this may explain the non-significant decrease in functional disability, as the program may need more than one month.

Literature review suggests that there is a growing body of welldesigned research to support the benefit of aerobic and strengthening exercise in RA. Muscle weakness in patients with RA may occur because of immobilization or reduction in activities of daily living. Maintenance of normal muscle strength is important not only for physical function but also for stabilization of the joints and prevention of traumatic injuries. It may be proposed that exercise therapy has beneficial effects on increasing physical capacity rather than reducing the activity of the disease [39]. This also may explain the nonsignificant decrease as the program include aerobic exercise only, and may be effective to combine aerobic exercise, strengthening and stretching for long time (more than one month). There are some limitations of this study. Firstly, the lack of follow-up for patients with RA for several periods post rehabilitation program to evaluate the long term effect of the Siwan therapy in pain and functional disability. Secondly, the absence of control group of patients with RA who received no treatment or only medical treatment as the author did not want to leave patients untreated through this period of time. Finally, certain secondary outcome variables such as, muscle strength and quality of life were not assessed. In conclusion, this study shows that Siwan therapy yields improvement in pain and functional disability on patients with RA than traditional physical therapy.

\section{References}

1. Jacobsson LT, Hanson RL, Knowler WC. Decreasing incidence and prevalence of rheumatoid arthritis in Pima Indians over a twenty-five-year period. Arthritis Rheum 1994, 37: 1158-1165.

2. Christina H, Stenstro M, Marian A. Minor strengthening exercise in rheumatoid arthritis, arthritis \& rheumatism. Arthritis Care Res 2003; 428-434.

3. Laan RFJM, van Riel PLCM, van der Putte LBA, van Erning LJTZO, vant Hof MA, Le mmens JA. Low dose prednisone induces rapid reversible axial bone loss in patients with rheumatoid arthritis: a randomized, controlled study. Ann Intern Med 1993; 119: 963-968

4. Wolfe F, Mitchell DM, Sibley JT, Fries JF, Bloch DA, Williams CA, Spitz PW, Haga M, Kleinheksel SM, Cathey MA. The mortality of rheumatoid arthritis. Arthritis Rheum 1994; 37: 481-494.

5. Gonzalez A, Maradit Kremers H, Crowson CS, Nicola PJ, Davis JM, Therneau TM, Roger VL, Gabriel SE. The widening mortality gap between rheumatoid arthritis patients and the general population. Arthritis Rheumatol 2007; 56: 3583-3587.

6. Lyn M, Claire B, Jean McQuade RN. Clinical guideline for the diagnosis and management of early rheumatoid arthritis. Royal Aus Coll Gene Pract 2009. 
7. Agarwal S. Newer nutritional basis in the management of rheumatoid arthritis. Electr Phys 2010; 2: 33-38.

8. Dilixat Y, Matiram S, Ayyulun S, Arkin S, Sekine M, Kagamimori S. Effects of sand bathing on heart rate, blood pressure, body temperature, weight and rheumatiod arthritis at Turpa, China. J Jap Assoc Phys Med Balneol Climatol 2001; 64: 210-212.

9. Griffith J, Carr A. What is the impact of early rheumatoid arthritis on the individual? Best Pract Res Clin Rheumatol 2001; 15: 77-90.

10. Jack. A. Philosophy of healing. Melbourne Inkata 1997; 36-38.

11. Aletaha D, Neogi T, Silman AJ, Funovits J, Felson DT, Bingham CO, Birnbaum NS, Burmester GR, Bykerk VP, Cohen MD, Combe B. 2010 rheumatoid arthritis classification criteria: an American College of Rheumatology/European League Against Rheumatism collaborative initiative. Arthritis Rheumatol 2010; 62: 2569-2581.

12. Berliner MN, Maurer AI. Effect of different methods of thermotherapy on skin microcirculation. Am J Phys Med Rehab 2004; 83: 292-297.

13. Foley RA. Transcutaneous electrical nerve stimulation. Manual for physical agents. Upper Saddle River (NJ) Prentice Hall 2000; 121-147.

14. Harkcom TM, Lampman RM, Banwell BF, Castor CW. Therapeutic value of graded aerobic exercise training in rheumatoid arthritis. Arthritis Rheumatol 1985; 28: 32-39.

15. Marc A. Pain measurement in P. prither Ray: pain medicine a comprehensive review. Mobsy Losangles California USA 2001; 36-37.

16. Wolfe F, Pincus T. Rheumatoid arthritis: pathogenesis, assessment, outcome, and treatment. Arthritis Rheumatol 1994.

17. Masuda A, Koga Y, Hattanmaru M, Minagoe S, Tei C. The effects of repeated thermal therapy for patients with chronic pain. Psychother Psychosom 2005; 74: 288-294.

18. Dilixat Y, Aytulun S, Ibadet R, Arkin S, Mayiram S, Sekine M, Kagamimori S. Effects of sand bathing on some physiological parameters with special reference to its use in the treatment of rheumatoid arthritis. Toyam Med Pharm Univ 2002; 65: 107-113.

19. Kirschner M, Gerhart J, Mitchison T. Molecular vitalism. Cell 2000; 100: 79-88.

20. Gaurav T, Ranjna C, Rukamani N, Manjunath RM. Study of inflammatory markers AND physical parameters in rheumatoid arthritis patients taking naturopathy \&AND anti-inflammatory agents. Help Age India Res Develop J $2012 ; 18$

21. Biswas K, Chattopadhyay I, Banerjee RK, Bandyopadhyay U. Biological activities and medicinal properties of neem (Azadirachta indica). Curr Sci Bangal 2002; 82: 1336-1345.

22. Gomes CD. Naturotherapies based on minerals. Geomaterials 2013; 3: 1.
23. Horikiri Y, Tei C, Tanaka N. Life management and rehabilitation of hypertension. JPN $\mathrm{J}$ Clinical and Experimental Med 1996; 73: 1277-1282.

24. Dawodu A, Davidson B, Woo JG, Peng YM, Ruiz-Palacios GM, Guerrero MD, Morrow AL. Sun exposure and vitamin $\mathrm{D}$ supplementation in relation to vitamin $\mathrm{D}$ status of breastfeeding mothers and infants in the global exploration of human milk study. Nutrients 2015; 7: 1081-1093.

25. Marques CD, Dantas AT, Fragoso TS, Duarte ÂL. The importance of vitamin D levels in autoimmune diseases. Revista Brasileira de Reumatologia 2010; 50: 67-80.

26. Linker-Israeli M, Elstner E, Klinenberg JR, Wallace DJ, Koeffler HP. Vitamin D3 and its synthetic analogs inhibit the spontaneous in vitro immunoglobulin production by SLE-derived PBMC. Clin Immunol 2001; 99: 82-93.

27. Cantorna MT, Mahon BD. Mounting evidence for vitamin $\mathrm{D}$ as an environmental factor affecting autoimmune disease prevalence. Exp Biol Med 2004; 229: 1136-1142.

28. Jones BJ, Twomey PJ. Issues with vitamin D in routine clinical practice. Rheumatology (Oxford) 2008; 47: 1267-1268.

29. Kandil HA. Remote Sensing in Egypt. Egyptian J Remote Sens Space Sci 2006; 9.

30. Kavuncu V, Evcik D. Physiotherapy in rheumatoid arthritis. MedGenMed 2004; 6: 3.

31. Melzack R, Wall PD. Pain mechanisms: a new theory. Surv Anesthesiol 1967; 11: 89-90.

32. Sluka KA, Walsh D. Transcutaneous electrical nerve stimulation: basic science mechanisms and clinical effectiveness. J Pain 2003; 4: 109-121.

33. Chen CC, Johnson MI, McDonough S, Cramp F. The effect of transcutaneous electrical nerve stimulation on local and distal cutaneous blood flow following a prolonged heat stimulus in healthy subjects. Clin Physiol Function Imag 2007; 27: 154-161.

34. Jong ZD, Munneke M, Zwinderman AH, Kroon HM, Jansen A, Ronday HK, Schaardenburg DV, Dijkmans BA, van den Ende $\mathrm{CH}$, Breedveld FC, Vliet Vliel TP, Hazes JM. Is a long-term high-intensity exercise program effective and safe in patients with rheumatoid arthritis? Results of a randomized controlled trial. Arthritis Rheum 2003; 48: 2415-2424.

35. Iversen MD, Fossel AH, Daltroy LH. Rheumatologistpatient communication about exercise and physical therapy in the management of rheumatoid arthritis. Arthritis Care Res 1999; 12: 180-192.

36. Finckh A, Iversen M, Liang MH. The exercise prescription in rheumatoid arthritis: primum non nocere. Arthritis Rheumatol 2003; 48: 2393-2395.

37. Lundberg IE, Nader GA. Molecular effects of exercise in patients with inflammatory rheumatic disease. Nat Rev Rheumatol 2008; 4: 597.

38. Van den Ende CH, Vliet Vlieland TP, Munneke M, Hazes JM. Dynamic exercise therapy for treating rheumatoid arthritis. Cochr Datab Syst Rev 2000; 1. 
The effect of Siwan therapy in management of patients with rheumatoid arthritis: a single blind randomized controlled trial

39. Stenstrom CH, Minor MA. Evidence for the benefit of aerobic and strengthening exercise in rheumatoid arthritis. Arthritis Rheum 2003; 49: 428-434.

\section{*Correspondence to}

Hamada Ahmed Hamada

Faculty of Physical Therapy

Cairo University

Egypt 